Aim of the study: This study aimed to evaluate the effect of percutaneous interventional treatment on obstructive jaundice caused by hepatocellular carcinoma with bile duct tumor thrombus.

Material and methods: A total of $16 \mathrm{pa}$ tients with bile duct tumor thrombus were included in the current retrospective study. All the patients were subjected to percutaneous transhepatic biliary drainage (PTBD). Treatment included permanent external drainage, internal drainage and routine tube adjustment, and covered stents according to the patients' clinical manifestations.

Results: The success rate of PTBD was $100 \%$. Among all the patients, two were treated with permanent external drainage, seven were treated with internal drainage and routine tube adjustment, and seven were treated with detaining covered stents. All the drainage tubes were successfully pulled out from the patients receiving covered stents. Among all the 16 patients, the clinical symptoms and life quality of 12 patients (12/16, $75 \%)$ were improved. The average survival time of all the patients was 203.7 days (ranging from 30 days to 391 days) with the median survival time of 199.5 days. Conclusions: Percutaneous interventional therapy for obstructive jaundice caused by hepatocellular carcinoma with bile duct tumor thrombus is a good choice. It improves patients' life quality. Permanent external drainage, internal drainage, and covered stents are alternative methods which should be chosen according to the patient's condition.

Key words: hepatocellular carcinoma, bile duct tumor thrombus, biliary drainage, covered stent.

\section{Clinical application of percutaneous drainage in treating hepatocellular carcinoma with bile duct tumor thrombus}

\author{
Zaiming Lu*, Wei Sun*, Feng Wen, Hongyuan Liang, Ming Shan, Qiyong Guo \\ Department of Radiology, Shengjing Hospital of China Medical University, Shenyang, \\ China \\ *These authors contributed equally to this study.
}

\section{Introduction}

Bile duct tumor thrombus (BDTT) is a major cause of hepatocellular carcinoma complicated with obstructive jaundice, and its incidence is $1.2 \%$ to $9.0 \%$ according to the literature [1-7]. Although the incidence is low, hepatocellular carcinoma complicated with obstructive jaundice can reduce patients' life quality greatly, and cause a bad prognosis and short survival time. Further, the incidence of BDTT has shown an increasing trend in recent years $[8,9]$. Therefore, to find an effective treatment method for BDTT is of great clinical significance.

Nowadays, treatment of hepatocellular carcinoma complicated with BDTT mainly adopts surgical and non-surgical methods. Surgical ablation of the primary lesion and the cancer thrombus can greatly improve patients' life quality, and prolong their survival time (sometimes it may even achieve long-term survival) [10-13]. However, most patients have to receive non-surgical treatment instead of surgical treatment due to factors such as tumor invasion, metastasis and postoperative recurrence when they visit the doctors [2].

Early effective bile duct drainage is the first step involved in non-surgical treatment, which can improve patients' hepatic function, and provide conditions for subsequent primary disease treatment. Nowadays, percutaneous transhepatic biliary drainage (PTBD) has become an important treatment method applied in palliative treatment of malignant obstructive jaundice. However, the application of PTBD in treatment of hepatocellular carcinoma complicated with obstructive jaundice has been reported only rarely. Even worse, most of these rare reports are case studies. Hence, due to insufficient clinical experience, the application of PTBD lacks clinical operative guidance. In addition, some authors believe that PTBD has only a limited effect on hepatocellular carcinoma complicated with obstructive jaundice [14, 15].

In order to explore the effect of percutaneous interventional treatment on obstructive jaundice caused by hepatocellular carcinoma with BDTT, the current study analyzed the clinical therapeutic processes of 16 patients suffering from obstructive jaundice caused by bile duct tumor thrombus and the patients' follow-up data retrospectively. The interventional drainage therapeutic procedures for types III and IV bile duct tumor thrombus were also preliminarily investigated.

\section{Material and methods}

\section{General data}

A total of 16 patients suffering from hepatocellular carcinoma with BDTT received treatment in Shengjing Hospital of China Medical University 
Table 1. Clinical features of the enrolled patients

\begin{tabular}{|c|c|c|c|c|c|c|c|}
\hline Case & Gender & Age & Tumor site (position)/size & BDT Type & Child grade & Portal vein invasion & Metastasis \\
\hline 1 & male & 59 & $\mathrm{~V}, \mathrm{VI} / 6 \times 5$ & III & B & right branch & no \\
\hline 2 & male & 46 & III, IV/5X3 & III & B & left branch & no \\
\hline 3 & male & 66 & I, VII, VIII/8X6 & IV & B & right branch & no \\
\hline 4 & female & 54 & $\mathrm{~V}, \mathrm{VI}, \mathrm{VIII} / 7 \mathrm{X} 5$ & III & B & no & no \\
\hline $5^{*}$ & male & 32 & undetermined & IV & B & no & lung \\
\hline 6 & male & 65 & undetermined & III & A & no & no \\
\hline 7 & female & 46 & II, III/4X3 & III & B & left branch & no \\
\hline 8 & male & 72 & I, VII, VIII/7X6 & IV & B & no & right adrenal gland \\
\hline $9^{*}$ & male & 52 & VIII/4X3 & III & $B$ & no & no \\
\hline 10 & male & 56 & IV, VII, VIII/8X5 & IV & B & no & no \\
\hline $11^{*}$ & male & 36 & undetermined & III & C & no & no \\
\hline 12 & male & 67 & I, V, VI/7X4 & III & B & right branch & no \\
\hline $13^{*}$ & female & 79 & undetermined & IV & B & no & no \\
\hline 14 & male & 53 & $\mathrm{~V}, \mathrm{VI} / 5 \mathrm{X} 4$ & III & B & right branch & lung \\
\hline $15^{\star}$ & male & 57 & undetermined & III & B & no & no \\
\hline 16 & female & 60 & $\mathrm{~V}, \mathrm{VI} / 6 \mathrm{X} 4$ & III & B & no & lung \\
\hline
\end{tabular}

Notes: 1) Locations of liver tumor were defined according to the segmental anatomy of Couinaud; 2) BDT (bile duct thrombus) was typed by the Ueda method; 3) *indicates that the patient was after operation

between January 2005 and December 2008. Among the patients, 12 were males and 4 were females. Their age ranged from 32 years to 79 years with an average of 56.3. All the patients presented with yellow skin and sclera. Meanwhile, 15 of the 16 patients experienced slight abdominal pain and distension, 12 had fever, and 9 complained of different degrees of skin itch.

Routine magnetic resonance cholangiopancreatography (MRCP) and/or enhancement CT scanning were carried out before treatment to evaluate the site and the degree of the neoplastic lesion and the biliary tract obstruction. Five patients were pathologically confirmed to have hepatocellular carcinoma after surgical resection, one was confirmed using puncture biopsy, seven were pathologically confirmed by detecting the tissues taken using biliary tract biopsy forceps, and three were confirmed using biochemical examination and iconography. Meanwhile, seven were confirmed with BDTT by detecting the tissues taken using biliary tract biopsy forceps, and the rest were confirmed using MRCP, CT scanning and percutaneous transhepatic cholangiography (PTC). Bile duct tumor thrombus was typed according to the Ueda BDTT typing criteria: 1) type I, in which the cancer thrombus is located in the cholangitic second branches; 2) type II, in which the cancer thrombus extends to the cholangitic first branches; 3 ) type III, in which the thrombus extends to the common hepatic duct (IIla), or the tumor sheds off the primary focus and then grows in the common hepatic duct (IIIb); and 4) type IV, in which the fragments of the tumor mobilize in the common hepatic duct [16]. In the current study, 11 patients suffered from type III, and 5 suffered from type IV. For hepatic function, one patient was graded as Child A, 14 were graded as Child B, and one was graded as Child C.
Patients satisfying any of the following criteria were excluded from the current study: excessive serous fluid, a serious hemorrhagic tendency, and no suitable pathway for puncture. All the general data of the patients in the current study are shown in Table 1.

\section{Methods}

All the patients received PTBD treatment. The puncture point was decided according to the patient's imaging data. Local anesthesia was performed using $2 \%$ lidocaine, and a 19-22 G bile duct puncture needle was then used for intra-hepatic puncture and ductal dilatation. A 0.035 in (1 in $=2.54 \mathrm{~cm}$ ) Radiofocus (Terumo, Japan) guide wire was inserted along the overtube, and cholangiography was then performed for bile duct invasion at different hepatic segments. The guide wire was inserted into the hepatic segment with the most obvious bile duct obstruction selectively, the overtube was extracted, and a biliary tract drainage tube or a pigtail internal-external drainage tube was implanted for internal drainage treatment. After surgery, permanent external drainage or a covered stent (at a diameter of $8 \mathrm{~mm}$ to $10 \mathrm{~mm}$ and a length of $50 \mathrm{~mm}$ to $80 \mathrm{~mm}$ ) was adopted according to changes in the patient's symptoms and the severity of jaundice.

\section{Follow-up and curative effect}

All the patients were followed up. The first follow-up was at 1 month after treatment. Then, the follow-up was carried out once every three months, and the total followup time was two years. The observation index was the survival time of the patient. General conditions of the patient such as the severity of abdominal pain and distention, the 
severity of skin itch, and presence or absence of fever were evaluated. At 2 weeks after the final interventional treatment, the TBIL (total bilirubin) level was detected, and the difference between before and after treatment was evaluated. The $t$ test was carried out, and $p<0.05$ was considered significant.

\section{Results}

Curative effect

The success rate of PTBD was $100 \%$. Among all the patients, two were treated with permanent external drainage, seven were treated with internal drainage and routine tube adjustment, and seven were treated with covered stents (including five with BDTT type IV and two with BDTT type III). All the drainage tubes were successfully pulled out from the patients receiving a covered stent (Figs. 1-3).

The normal bilirubin range for TBIL is from $3.4 \mu \mathrm{mol} / \mathrm{l}$ to $20.5 \mathrm{\mu mol} / \mathrm{l}$. Of all the 16 patients, the TBIL level at 2 weeks after interventional treatment fell by between $67.9 \mu \mathrm{mol} / /$ and $312.5 \mu \mathrm{mol} / \mathrm{l}$, with an average of $161.2 \pm 80.5 \mu \mathrm{mol} / \mathrm{l}$, which was $11.6 \mu \mathrm{mol} / \mathrm{l}$ to $185.1 \mu \mathrm{mol} / \mathrm{l}$ lower than that before treatment $(261.9 \pm 77.2 \mu \mathrm{mol} / \mathrm{l})$. The average increase was 100.7 $\pm 54.7 \mu \mathrm{mol} / \mathrm{l}$, showing a statistical difference $(t=7.366$,
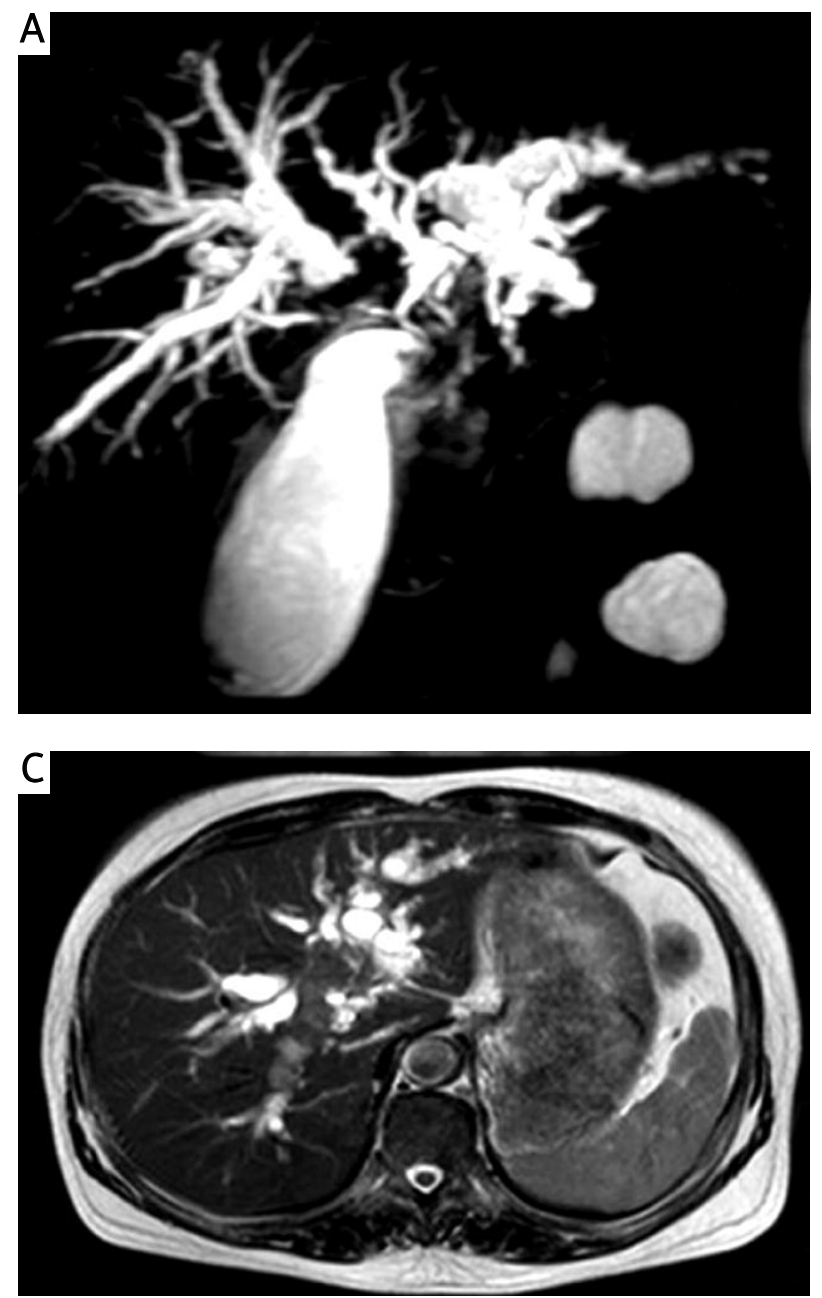

$p<0.01)$. The TBIL level of 12 cases was decreased by $30 \%$ (Table 2).

After treatment, the symptoms of abdominal pain and distension disappeared in 8 patients, temperature returned to normal in 7 patients, fever was relieved in 3 patients, and the symptoms of skin itch disappeared in 9 patients (9/9).

\section{Follow-up}

All the patients died within the two-year follow-up. Their survival time ranged from $30 \mathrm{~d}$ to 391 days with an average of $204 d$ and a median time of 200 days.

The serum total bilirubin of one patient who received covered stent treatment was decreased below 20 m mol/l. After transcatheter arterial embolization (TAE) treatment twice, the patient's survival time was 305 days.

\section{Complications}

The complications of interventional treatment include hemorrhage and infection. Of all the patients, immediate biliary hemorrhage after puncture occurred in 5 patients $(5 / 16$, $31.2 \%)$. This symptom was relieved after venous hemostatic administration. Blood-containing liquid of more than $500 \mathrm{ml}$ that drained through the drainage tube during the drainage
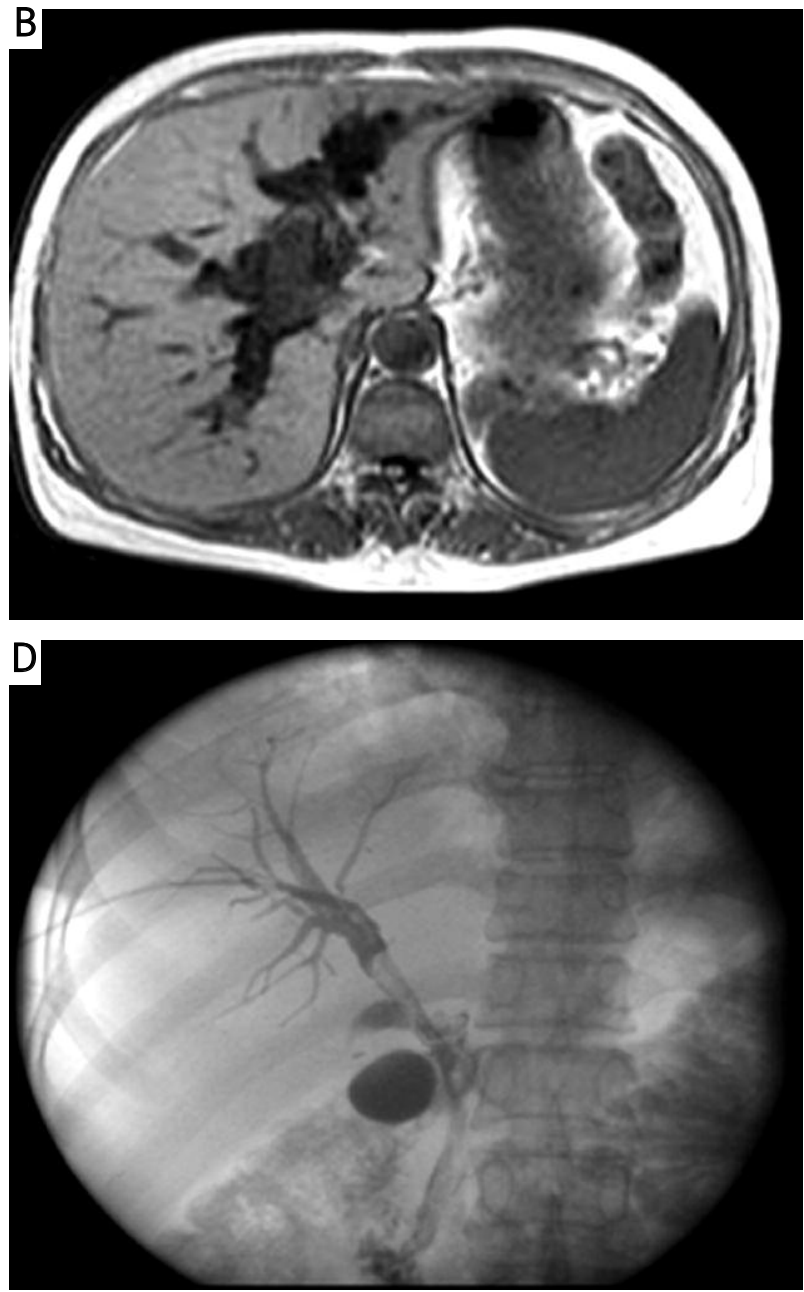

Fig. 1. Confirmed hepatic carcinoma in a 65-year-old male using biopsy. A-C) MRCP indicates a bile duct lesion in the hepatic hilar region; D) PTC shows the filling defects in the hepatic hilar bile duct and a type III bile duct thrombus 


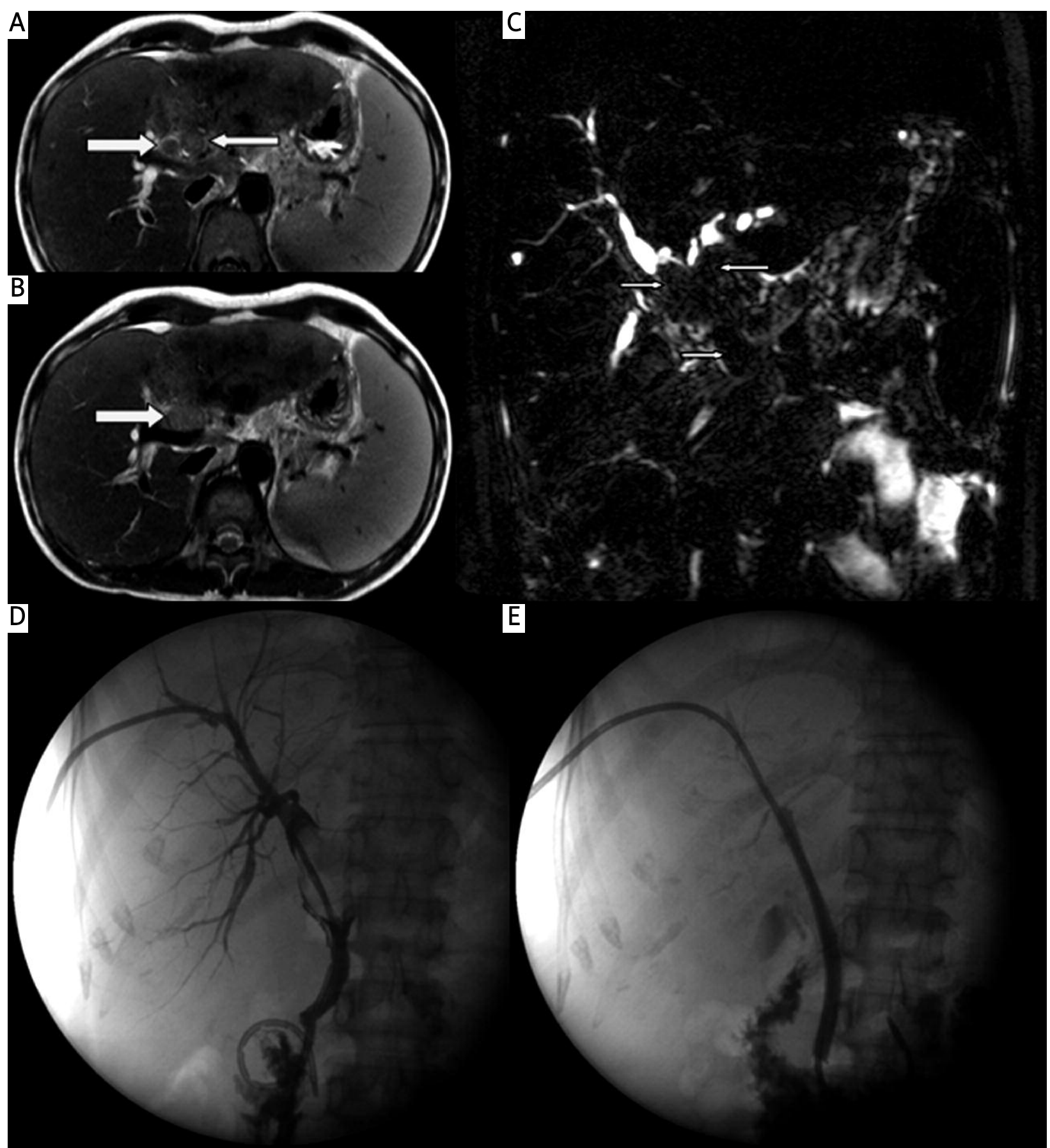

Fig. 2. Confirmed hepatic carcinoma in a 59-year-old male using biopsy. A-C show the type III bile duct thrombus; D and E show the covered stent implanted after internal drainage

period was found in 9 patients. They were also companied with melena or positive fecal occult blood. Such symptoms were lessened after adjustment of the drainage tube and the administration of hemostatics. Confirmed fever and an increase in leucocytes which were accompanied with biliary hemorrhage were found in 3 patients. The hemorrhage was stopped, and the symptoms were relieved after systemic antiinflammatory treatment. Shedding of the drainage tube was found in one patient who received external drainage. This phenomenon was caused by an external force from the patient. The second successful external drainage treatment was then performed.
No remission of BDTT after drainage was found in one patient, who also had fever and drainage quantity of no more than $100 \mathrm{ml}$ every day. Even after adjustment to external drainage, discontinuous biliary tract hemorrhage still occurred; this was complicated with liver and kidney failure at the late stage. The patient died $30 \mathrm{~d}$ later after treatment.

\section{Discussion}

About $40 \%$ of hepatocellular carcinoma patients have jaundice, which is mainly caused by severe hepatic cirrhosis and extensive tumor invasion [17]. However, jaundice caused by hepatocellular carcinoma complicated with BDTT is rarely 


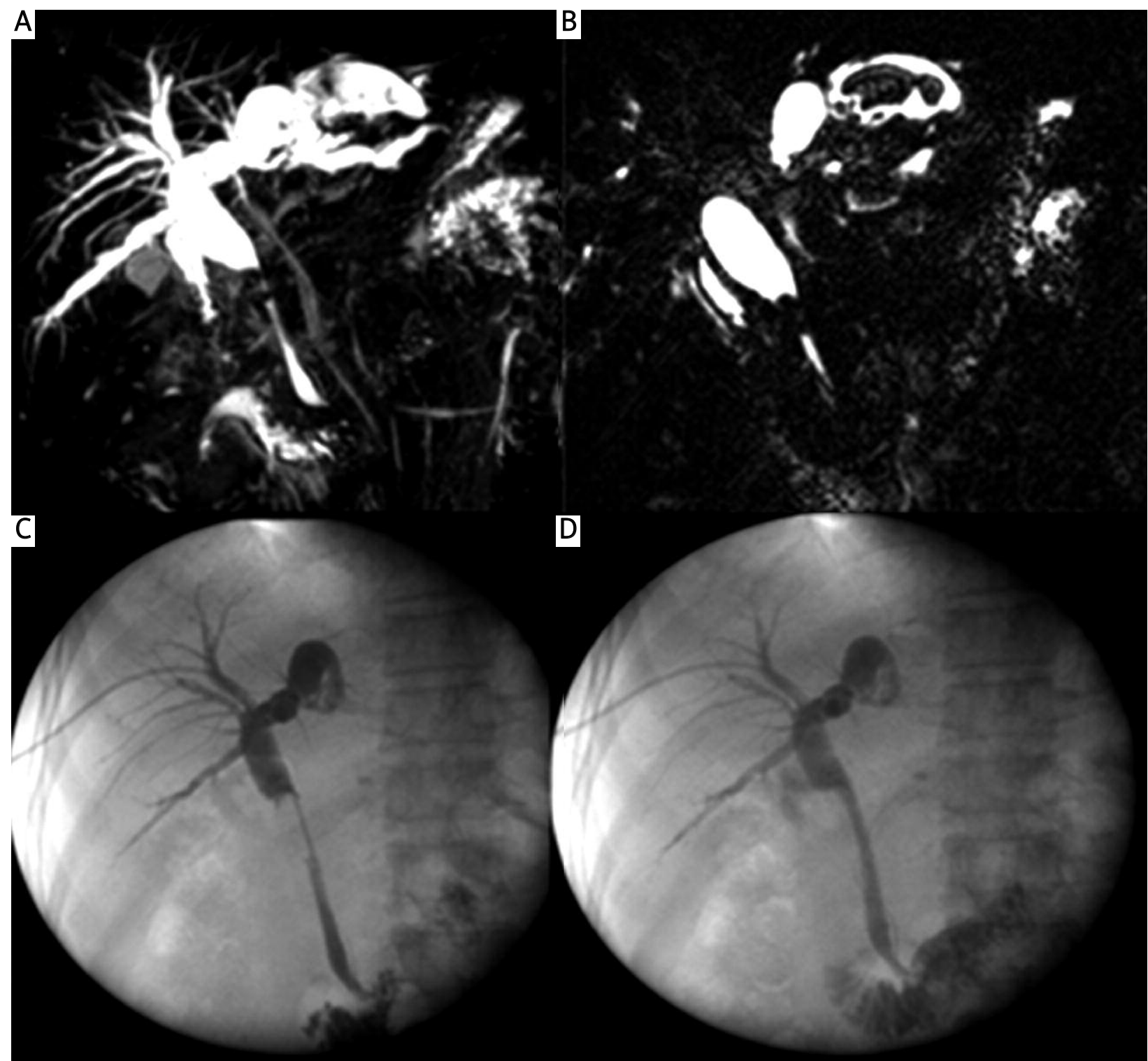

Fig. 3. A type IV bile duct thrombus in a female after hepatocellular carcinoma operation. A and B show the invasion into the common bile duct; $\mathbf{C}$ and $\mathrm{D}$ show successful implantation of a covered stent after internal drainage

seen. Mallory et al. first described such a disease in 1947 [18]. According to them, hepatocellular carcinoma invades into the cystic duct to cause tumor thrombus shedding and biliary tract hemorrhage, which further lead to obstructive jaundice. Lin et al. reported 8 cases of jaundice caused by hepatocellular carcinoma invasion into the bile duct in 1975, and first put forward the clinical classification criteria for icteric type hepatocellular carcinoma [19].

Generally, BDTT is thought to be developed from primary hepatocellular carcinoma through the follow channels: 1) hepatocellular carcinoma cells invade into the intra-hepatic bile duct forming thrombus, and the thrombus and the primary lesion then grow dumbbell-like, blocking the biliary tract; 2) hepatocellular carcinoma cells break away from the primary focus, and immigrate into the lumen between the intraand extra-hepatic bile ducts, forming a blockage; 3) hepatocellular carcinoma cells invade into the portal vein or the lymphatic vessel first, and then invade into the bile duct wall;
4) portal vein thrombus invades into its adjacent bile duct; 5) hepatocellular carcinoma cells invade into the bile duct wall through the spaces between nerve sheaths; and 6) the cancer invades into the nutrient blood vessels in the bile duct wall first, and then breaks through the cholangitic epithelium into the biliary lumen. In recent years, with the development of imaging and treatment techniques [3, 20], the understanding of BDTT has greatly improved, and more and more treatment methods have also been developed.

An ideal therapy for hepatocellular carcinoma complicated with BDTT is to remove the lesion tissues surgically. As BDTT rarely invades into the bile duct wall, it is not difficult to remove during exploration of the biliary tract $[11,19]$. Commonly adopted surgical methods include lobectomy of the liver (including the primary tumor and the BDTT), hepatectomy with removal of BDTT, and thrombectomy through choledochotomy followed by $T$ tube drainage. Compared with the third method, the former two can achieve better prog- 
Table 2. Outcomes of interventional treatment

\begin{tabular}{|c|c|c|c|c|c|c|c|c|c|c|c|}
\hline \multirow[t]{2}{*}{ Cases } & \multirow[t]{2}{*}{$\begin{array}{l}\text { Interventional } \\
\text { methods }\end{array}$} & \multirow[t]{2}{*}{ Complication } & \multicolumn{2}{|c|}{$\begin{array}{l}\text { Total bilirubin } \\
(\mu \mathrm{mol} / \mathrm{l})\end{array}$} & \multicolumn{2}{|c|}{${ }^{*}$ Fever } & \multicolumn{2}{|c|}{$\begin{array}{c}\text { Stomach ache, } \\
\text { abdominal } \\
\text { distension }\end{array}$} & \multicolumn{2}{|c|}{ Skin itch } & \multirow{2}{*}{$\begin{array}{c}\begin{array}{c}\text { Follow-up } \\
\text { and }\end{array} \\
\text { survival time } \\
\text { (day) }\end{array}$} \\
\hline & & & before & after & before & after & before & after & before & after & \\
\hline 1 & internal drainage & biliary tract bleeding & 312.5 & 287.4 & + & - & + & + & + & - & 95 \\
\hline 2 & internal drainage & biliary tract bleeding & 157.4 & 90.1 & ++ & + & + & - & - & - & 194 \\
\hline 3 & PTBD+ covered stent & no & 402.5 & 217.4 & + & - & + & - & + & - & 269 \\
\hline 4 & permanent drainage & $\begin{array}{l}\text { biliary tract bleeding, } \\
\text { infection }\end{array}$ & 298.9 & 287.3 & - & + & + & + & - & - & 30 \\
\hline 5 & PTBD+ covered stent & biliary tract bleeding & 232.6 & 107.5 & + & - & + & + & - & - & 306 \\
\hline 6 & PTBD+ covered stent & no & 197.9 & 73.4 & - & - & - & - & + & - & 298 \\
\hline 7 & internal drainage & biliary tract bleeding & 156.3 & 105.2 & ++ & + & + & - & - & - & 143 \\
\hline 8 & PTBD+ covered stent & no & 307.4 & 174.3 & + & - & + & - & + & - & 305 \\
\hline 9 & internal drainage & biliary tract bleeding & 205.7 & 147.6 & + & + & + & - & - & - & 116 \\
\hline 10 & PTBD+ covered stent & no & 375.4 & 203.5 & ++ & - & + & + & + & - & 273 \\
\hline 11 & PTBD+ covered stent & no & 275.9 & 103.7 & + & - & + & - & - & - & 391 \\
\hline 12 & internal drainage & biliary tract bleeding & 304.1 & 179.6 & ++ & + & + & + & + & - & 146 \\
\hline 13 & PTBD+ covered stent & no & 216.2 & 87.6 & + & - & + & - & + & - & 205 \\
\hline 14 & internal drainage & $\begin{array}{l}\text { biliary tract bleeding, } \\
\text { infection }\end{array}$ & 352.1 & 312.5 & + & ++ & + & + & + & - & 117 \\
\hline 15 & internal drainage & no & 189.3 & 67.9 & - & - & + & + & - & - & 235 \\
\hline 16 & permanent drainage & $\begin{array}{l}\text { biliary tract bleeding, } \\
\text { infection }\end{array}$ & 206.5 & 134.2 & - & + & + & - & + & - & 136 \\
\hline
\end{tabular}

Notes: 1) PTBD is short for percutaneous transhepatic biliary drainage; 2) two-week observation after interventional treatment; 3) fever: ++ for a high fever, + for a low fever, and-for normal temperature; abdominal pain and distension: + for positive signs, and-for negative signs.

nosis. The average survival time of patients treated with them exceeds two years $[5,10,11]$. In addition, hepatic transplantation can also serve as an effective alternative treatment method, which can achieve a median survival time of more than 20 months [22].

However, although surgical treatment can achieve good effects, most patients have missed the best time for surgery at the time of disease onset, or they refuse to receive surgical treatment due to various reasons. Nowadays, PTBD has been widely considered as an important palliative treatment method for obstructive jaundice. It has been extensively applied in clinical practice. Percutaneous transhepatic biliary drainage mainly takes the forms of external drainage, internal and external drainage, and internal drainage. In the present study, all the patients were successfully treated with PTBD, which was consistent with results reported in the literature $[13,15]$. All these results indicate that the application of PTBD in treatment of obstructive jaundice caused by hepatocellular carcinoma is feasible.

However, interventional treatment of hepatocellular carcinoma and BDTT complicated with obstructive jaundice lacks a systemic and normative method. In addition, authors disagree on the curative effect of PTBD; some of them think this method can only achieve a limited effect. The level of serum bilirubin in only 2 patients out of 13 patients who suffered from hepatocellular carcinoma complicated with obstructive jaundice is reduced by more than $50 \%$ at $20 \mathrm{~d}$ after PTBD [13]. The effective rate of PTBD among 22 patients suffering from hepatocellular carcinoma with obstructive jaundice is only $59.1 \%$ [15]. However, in the current study, PTBD achieved a much better effective rate (75\%). Presumably, this better effect is correlated with the following factors: 1) drainage tubes and biliary stents with large diameters were applied in the present study, which enlarged the ducts maximally to achieve sufficient drainage; this method can overcome the drawback of inadequate drainage caused by internal prostheses with small diameters; 2) all the cases in the present study belonged to BDTT type III or IV, in which the invaded area of the intra-hepatic bile ducts was small and the PTBD drainage scope was large; and 3) as BDTT is a soft obstruction, it is apt to relapse into biliary tract strutting, and meanwhile it is often complicated with hemorrhage, which make treatment run into a predicament greatly limiting the application of metal bare stents; however, this problem was partially solved in the present study by adopting covered stents and different means of drainage.

To date, the effect of interventional PTBD on survival time of patients suffering from hepatocellular carcinoma and BDTT complicated with obstructive jaundice has only been rarely reported. In the current study, the average survival time of the patients was $204 \mathrm{~d}$ after PTBD treatment, which was close to the results obtained by adopting stent treatment [23, 24]. 
This result was longer than the average time (135d) obtained after simple biliary T tube drainage [25]. Covered stents can reduce external biliary drainage quantity, enlarge the drainage area, and promote the prolongation of the stent patency period, which might be an important reason for such a better effect on patients' survival time. But PTBD is only the first step of palliative treatment. When the patient's hepatic function is improved, TAE or even surgery should be taken actively for primary diseases. In the current study, one patient received TAE treatment, and his survival time reached $305 \mathrm{~d}$, which was basically consistent with the survival time (11 months) reported in the literature [25-27].

Bile duct tumor thrombus separates from the primary focus, and moves downwards to the extra-hepatic bile duct, causing biliary duct blockage, which is the main mode of biliary obstruction caused by BDTT types III and IV. The invasion of cancer cells into the bile duct wall causes hemorrhage, and the sludged blood containing cancer cells blocks the biliary tract, which can coexist with the modes [27-29]. Therefore, BDTT easily induces hemorrhage. This characteristic brings a tough problem to interventional treatment on the one hand. On the other hand, it becomes the main cause for the occurrence of complications such as biliary tract hemorrhage, inadequate drainage, concurrent infection, and so on. Based on the above, a detained drainage tube is of great necessity after successful puncture, which can be very helpful in sufficient drainage and pathologic condition evaluation. In the current study, all the patients received an internal drainage tube first. Considering the limitation and location (in the common bile duct) of the thrombus in patients with BDTT type IV, to detain a covered stent will be the best choice for internal drainage. This method was proved applicable by the current study, in which all the patients with BDTT type IV received covered stent treatment successfully, and the drainage tubes were all pulled out. Meanwhile, considering that BDTT type III is easily complicated with biliary tract hemorrhage, the patients with BDTT type III in the current study were observed routinely for 5 days to 10 days, and different drainage methods were then decided according to their postoperative manifestations. Two patients received permanent external drainage treatment due to complications of biliary hemorrhage and infection in the current study. Meanwhile, straight drainage tubes were adopted rather than commonly used pigtail-like ones in the current study. The drainage tube entered into an intra-hepatic bile duct at a hepatic segment, and transferred into another intra-hepatic bile duct via the confluence region. This type of detainment can not only increase the stability of the drainage tube, but also guarantee more sufficient drainage, and improve the symptoms of obstructive jaundice maximally.

To the best of our knowledge, the current study is the only systemic study on the procedures of interventional therapy for obstructive jaundice caused by hepatocellular carcinoma and BDTT up to now. However, a larger sample size is still needed in the future in order to further certify the results obtained in the current study.

To draw a conclusion, PTBD is an applicable method for patients with BDTT, especially for those who cannot receive surgical treatment; it can improve patients' life quality, and create conditions for further treatment of primary dis- eases; covered stents can be applied for patients with BDTT type IV, whereas for patients with type III, covered stents, permanent external drainage, or internal drainage should be chosen according to their specific conditions; further, bare metal stents are not advisable for patients with BDTT.

The present study was supported by Innovation Team Fund of Liaoning Education Department (No. 2007T182).

\section{References}

1. Kojiro M, Kawabata K, Kawano Y, Shirai F, Takemoto N, Nakashima T. Hepatocellular carcinoma presenting as intrabile duct tumorgrowth-a clinicopathologic study of 24 cases. Cancer 1982; 49: 2144-7.

2. Qin LX, Tang ZY. Hepatocellular carcinoma with obstructive jaundice: diagnosis, treatment and prognosis. World J Gastroenterol 2003; 9 : 385-91.

3. Liu O, Chen J, Li H, Liang B, Zhang L, Hu T. Hepatocellular carcinoma with bile duct tumor thrombi: correlation of magnetic resonance imaging features to histopathologic manifestations. Eur J Radiol 2010; 76: 103-9.

4. Shiomi M, Kamiya J, Nagino M, et al. Hepatocellular carcinoma with biliary tumor thrombi: aggressive operative approach after appropriate preoperativemanagement. Surgery 2001; 129: 692-8.

5. Peng SY, Wang JW, Liu YB, Cai XJ, Deng GL, Xu B, Li HJ. Surgical intervention for obstructive jaundice due to biliary tumor thrombus in hepatocellular carcinoma. World J Surg 2004; 28: 43-6.

6. Peng BG, Liang LJ, Li SQ, Zhou F, Hua YP, Luo SM. Surgical treatment of hepatocellular carcinoma with bile duct tumor thrombi. World J Gastroenterol 2005; 11: 3966-9.

7. Daduang J, Limpaiboon T, Daduang S. Biomarker to distinguish hepatocellular carcinoma from cholangiocarcinoma by serum a disintegrin andmetalloprotease 12. Arch Med Sci 2011; 7: 1013-6.

8. Sugiura T, Nagino M, Ebata T, Arai T, Oda K, Yuasa N, Nimura Y. Treatment of colorectal liver metastasis with biliary and portal vein tumor thrombi by hepatopancreatoduodenectomy. J Hepatobiliary Pancreat Surg 2006; 13: 256-9.

9. Soyer P, Laissy JP, Bluemke DA, Sibert A, Menu Y. Bile duct involvement in hepatocellular carcinoma: MR demonstration. Abdom Imaging 1995; 20: 118-21.

10. Esaki M, Shimada K, Sano T, Sakamoto Y, Kosuge T, Ojima H. Surgical results for hepatocellular carcinoma with bile duct invasion: a clinicopathologic comparison between macroscopic and microscopic tumor thrombus. J Surg Oncol 2005; 90: 226-32.

11. Xiangji L, Weifeng T, Bin Y, Chen L, Xiaoqing J, Baihe Z, Feng S, Mengchao W. Surgery of hepatocellular carcinoma complicated with cancer thrombi in bile duct: efficacy for criteria for different therapy modalities. Langenbecks Arch Surg 2009; 394: 1033-9.

12. Yu XH, Xu LB, Liu C, Zhang R, Wang J. Clinicopathological characteristics of 20 cases of hepatocellular carcinoma with bile duct tumor thrombi. Dig Dis Sci 2011; 56: 252-9.

13. Joanna Omyła-Staszewska, Andrzej Deptała. Effective therapeutic management of hepatocellular carcinoma - on the basis of a clinical case. Wspolczesna Onkol 2012; 16: 64-7.

14. Kubota Y, Seki T, Kunieda K, et al. Biliary endoprosthesis in bile duct obstruction secondary to hepatocellular carcinoma. Abdom Imaging 1993; 18: 70-5.

15. Lee JW, Han JK, Kim TK, Choi BI, Park SH, Ko YH, Yoon CJ, Yeon KM. Obstructive jaundice in hepatocellular carcinoma: response after percutaneous transhepatic biliary drainage and prognostic factors. Cardiovasc Intervent Radiol 2002; 25: 176-9.

16. Ueda M, Takeuchi T, Takayasu T, et al. Classification and surgical treatment of hepatocellular carcinoma (HCC) with bile duct thrombi. Hepatogastroenterology 1994; 41: 349-54.

17. Wang HJ, Kim JH, Kim JH, Kim WH, Kim MW. Hepatocellular carcinoma with tumor thrombi in the bile duct. Hepatogastroenterology 1999; 46: 2495-9. 
18. Mallory TB, Castleman B, Parris EE. Case records of the Massachusetts General Hospital. N Eng J Med 1947; 237: 673-6.

19. Lin TY, Chen KM, Chen YR, Lin WS, Wang TH, Sung JL. Icteric type hepatoma. Med Chir Dig 1975; 4: 267-70.

20. Liu QY, Huang SQ, Chen JY, Li HG, Gao M, Liu C, Liang BL. Small hepatocellular carcinoma with bile duct tumor thrombi: CT and MRI findings. Abdom Imaging 2010; 35: 537-42.

21. Ikenaga N, Chijiiwa K, Otani K, Ohuchida J, Uchiyama S, Kondo K. Clinicopathologic characteristics of hepatocellular carcinoma with bile duct invasion. J Gastrointest Surg 2009; 13: 492-7.

22. Lee KW, Park JW, Park JB, et al. Liver transplantation for hepatocellular carcinoma with bile duct thrombi. Transplant Proc 2006; 38: 2093-4.

23. Lau W, Leung K, Leung TW, Liew CT, Chan MS, Yu SC, Li AK. A logical approach to hepatocellular carcinoma presenting with jaundice. Ann Surg 1997; 225: 281-5.

24. Okazaki M, Mizuta A, Hamada N, Kawamura N, Nakao K, Kikuchi T, Osada T. Hepatocellular carcinoma with obstructive jaundice successfullfy treated with a selr-expandable metallic stent. J Gastroenterol 1998; 33: 886-90.

25. Hu J, Pi Z, Yu MY, Li Y, Xiong S. Obstructive jaundice caused by tumor emboli from hepatocellular carcinoma. Am Surg 1999; 65: 406-10.

26. Okuda M, Miyayama S, Yamashiro M, et al. Sloughing of intraductal tumor thrombus of hepatocellular carcinoma after transcatheter arterial chemoembolization. Cardiovasc Intervent Radiol 2010; 33: 619-23.

27. Simon K, Serafińska S, Pazgan-Simon M. Surveillance programs for early detection of hepatocellular carcinoma. Wspolczesna Onkol 2012; 16: 295-9.

28. Narita R, Oto T, Mimura Y, et al. Biliary obstruction caused by intrabiliary transplantation from hepatocellular carcinoma. J Gastroenterol 2002; 37: 55-8.

29. Wang JH, Chen TM, Tung HD, Lee CM, Changchien CS, Lu SN. Color Doppler sonography of bile duct tumor thrombi in hepatocellular carcinoma. J Ultrasound Med 2002; 21: 767-72.

\section{Address for correspondence}

Dr. Zaiming Lu and Dr. Qiyong Guo

Department of Radiology

Shengjing Hospital of China Medical University

36 Sanhao Street, Heping District

Shenyang, 110004, China

tel. 86-24-31319131, fax 86-24-23929902

e-mail: qiyongguocn@126.com

Submitted: 20.07.2012

Accepted: 27.11 .2012 